\title{
Research on the integration and scheduling method of intelligent cloud manufacturing resources for fully mechanized coal mining equipment
}

Juanli Li ( $\square$ lijuanli@tyut.edu.cn )

Taiyuan University of Technology https://orcid.org/0000-0002-1190-9119

Mengzhen Sun

Taiyuan University of Technology College of Mechanical and Vehicle Engineering

Shuo Jiang

Taiyuan University of Technology College of Mechanical and Vehicle Engineering

Jiacheng Xie

Taiyuan University of Technology College of Mechanical and Vehicle Engineering

Xuewen Wang

Taiyuan University of Technology College of Mechanical and Vehicle Engineering

\section{Research}

Keywords: fully mechanized coal mining equipment, resource integration, cloud manufacturing, cloud scheduling, genetic algorithm

Posted Date: April 28th, 2020

DOl: https://doi.org/10.21203/rs.3.rs-24789/v1

License: (c) (1) This work is licensed under a Creative Commons Attribution 4.0 International License. Read Full License 


\section{Title page}

Article Title: Research on the integration and scheduling method of intelligent cloud manufacturing resources for fully mechanized coal mining equipment

Authors: Juanli Li ${ }^{\mathrm{a}}$, Mengzhen Sun ${ }^{\mathrm{a}}$, Shuo Jiang ${ }^{\mathrm{a}}$, Jiacheng Xie ${ }^{\mathrm{a}, \mathrm{b}}$, Xuewen Wang ${ }^{\mathrm{a}}$ Author affiliations:

a.College of Mechanical and Vehicle Engineering, Key Laboratory of Fully Mechanized Coal Mining Equipment, Taiyuan University of Technology, Shanxi 030024, China

b.Taiyuan Mining Machinery Group Co. ,Ltd. Postdoctoral science research workstation,Taiyuan 030032, China

Corresponding author name:Juanli $\mathrm{Li}$

\section{Affiliation:}

College of Mechanical Engineering, Key Laboratory of Fully Mechanized Coal Mining Equipment, Taiyuan University of Technology, Shanxi 030024,China

Detailed permanent address:

Taiyuan University of Technology, No. 79 Yingze West Street, TaiYuan, ShanXi Province, P. R.

China

Email address:lijuanli@tyut.edu.cn

Telephone number:86-13994232476;

\section{Funding:}

This work was supported by the Shanxi Province Nature Science Fund Project under Grant 201901D111056, Shanxi Province Graduate Education Reform Research Topic under Grant 2019JG047, and the China Postdoctoral Science Foundation under Grant 2019M651081.

\section{Authors' contributions:}

All authors designed the project and participated in the experiments and the interpretation of the results. Conceptualization, J. Li; methodology, M. Sun; software, S. Jiang and J. Xie; writing-original draft preparation, J. Li; writing-review and editing, X. Wang.

\section{Conflicts of Interest:}

The authors declare no conflict of interest. 


\title{
Research on the integration and scheduling method of intelligent cloud manufacturing resources for fully mechanized coal mining equipment
}

\begin{abstract}
In view of the problems such as the overall low utilization rate of resources, the insufficient level of industry informatization, the prominent problem of repeated construction, and the insufficient level of innovation in the manufacturing process design of fully mechanized coal mining equipment, the integration and scheduling method of intelligent cloud manufacturing resources for fully mechanized coal mining equipment was studied. First, the necessity and importance of building intelligent cloud manufacturing resources integration and scheduling systems for fully mechanized mining equipment under the current situation were analyzed. Then, based on the underlying services of cloud computing and intelligent cloud manufacturing, the overall architecture of intelligent cloud manufacturing resources integration and scheduling systems for fully mechanized coal mining equipment was proposed, and the intelligent cloud manufacturing resources integration platform suitable for general and special technical services was designed. Then, a could scheduling method based on an adaptive genetic algorithm was proposed to realize the scheduling of cloud manufacturing resources. Finally, the practicability and operability of the system were verified by the cases. This study has realized the integration and sharing of resources, such as the design, calculation, data, simulation, and servicing of fully mechanized coal mining equipment under the intelligent cloud manufacturing environment.
\end{abstract}

Key words: fully mechanized coal mining equipment; resource integration; cloud manufacturing; cloud scheduling;genetic algorithm

\section{Introduction}

The manufacturing industry is the main body of real economy, the material basis of national security, and a reason for people's happiness and well-being. It also reflects a country's scientific and technological development level [1]. Therefore, governments of all countries always invest in the development of their manufacturing industries. For example, the high-tech strategic plan "industry 4.0 " proposed by the German government aims to establish an intelligent and advanced manufacturing mode that is integrated with the Internet and which would improve the manufacturing efficiency, reduce its costs, and accelerate its response [2]. Also, the "made in China 2025" plan proposed by the Chinese government defines intelligent manufacturing as the main direction of China's manufacturing industry and aims at accelerating the construction of a strong manufacturing power, the development of an advanced manufacturing industry, and the deep integration of the Internet, big data, artificial intelligence, and real economy [3]. In addition, in its new strategic layout, the USA promotes the usage of the industrial Internet to subvert the value system of the manufacturing industry and use digital, new materials and new production methods to subvert the production mode of the manufacturing industry. With the rapid development of science and technology, the development of the manufacturing industry depends more on the promotion of high-tech applications. Li Bohu, an academician of the Chinese Academy of engineering, innovated a networked manufacturing mode by combining cloud computing, highperformance computing, IOT, and other technologies to propose the concept of cloud manufacturing $[4,5]$. Then, he developed a new information and manufacturing technology and proposed the concept of "intelligent cloud manufacturing" [6], providing a good solution for the management, integration, sharing, and scheduling of manufacturing enterprise resources. Under this guidance, the cloud manufacturing technology has made significant progress $[7,8]$.

Coal is one of the important energy pillar industries in the world, and its fully mechanized mining equipment (including roadheaders, crushers, shearers, scraper conveyors, transfer machines, water pumps, and mine hoists) play a significant role in coal mining. However, at present, the resources of design and manufacture of fully mechanized coal mining equipment are mainly scattered in colleges and universities, scientific research institutes, and enterprise technology research and development centers. The overall utilization rate of these resources is low, the industry information level is not enough, the problem of repeated construction is prominent, the design innovation is insufficient, and the effective resources sharing cannot be realized, and this has undermined the sustainable development of manufacturing coal mining equipment. At the same time, with the increasing market competition,the level of using information technology to transform traditional production mode and technological process of coal machine manufacturing enterprises needs to be improved urgently, so these enterprises have a strong demand for manufacturing resources [9]. This contradiction is the main problem to be solved in this study.

In recent years, intelligent cloud manufacturing has made a lot of breakthroughs in academic research and industrial applications. Many scholars have studied several key issues, such as service composition optimization strategies, platform security architecture, and scheduling in a cloud manufacturing environment [10-15], which provides useful references for the research in this study. In comparison with common engineering machinery, fully mechanized coal mining equipment are challenged with weak network transmission signals, difficult data and knowledge collection, complex manufacturing processes, and high manufacturing 
costs due to their complex structure and difficult operating environments. Based on the technologies of mechanical design, advanced sensors, virtual simulation, monitoring and diagnosis, the Internet, genetic algorithms, this study studies the key technical issues facing the intelligent cloud manufacturing resources integration and scheduling of fully mechanized coal mining equipment while taking into consideration large-scale mining and transportation equipment, such as high mining electric traction shearers, super-heavy scraper conveyors, pump stations, crushers, roadheaders, and mine hoists. Also, the intelligent cloud manufacturing resources integration and scheduling system for mining and transporting various kinds of coal mining mechanical equipment was constructed, and the manufacturing resources, such as model selection designs, parametric modeling, virtual assembly and demonstration, equipment monitoring and diagnosis, computer aided engineering (CAE) analysis, knowledge management, key design technical services, general support systems, literature retrieval, technical training, practical technologies, and the regulations and standards required for mechanical design, were integrated. Moreover, the scheduling problem of cloud manufacturing resources was studied in-depth, and this study has realized the integration and sharing of resources, including the design, calculations, data, simulations, services of coal mining, and transportation equipment under a cloud manufacturing environment.

\section{An overall design of intelligent cloud manufacturing resources integration and scheduling system for fully mechanized mining equipment}

\subsection{Key infrastructure of cloud intelligent manufacturing}

The industrial Internet is the infrastructure that supports key integrated information of intelligent manufacturing. Through a comprehensive and deep perception, real-time dynamic transmission, and advanced modeling analysis of industrial data, intelligent decision-making and control are necessary to drive the intelligent development of the whole manufacturing industry (Fig.1). In this study, the industrial Internet that connects relevant productive enterprises and technology research centers of fully mechanized coal mining equipment in Shanxi Province in China is established through a mobile special line. It aims to link the resources relative to the design, manufacturing, and information of relevant universities and enterprises, and it realizes the overall sharing of resources through the construction of the industrial Internet.

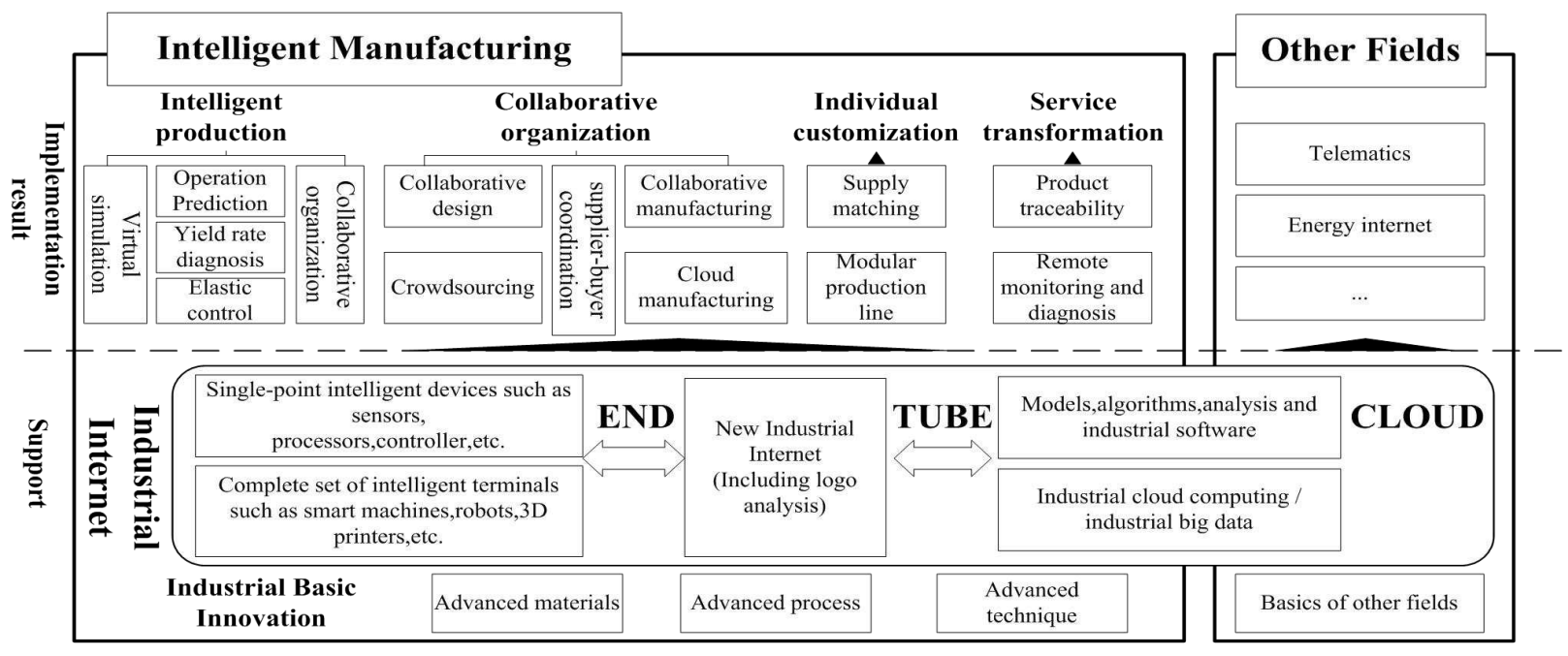

Fig.1 The supporting frame of industrial internet

\subsection{Architecture of cloud manufacturing resources integration and scheduling system}

Cloud manufacturing is proposed and developed on the basis of cloud computing. Based on the concept of "everything is service" in cloud computing, the concept of "manufacturing is service" is proposed. Generally, IaaS (Infrastructure-as-a- Service), PaaS (Platform-as-a-Service), and SaaS (Software-as-a-Service) are three service modes of cloud computing [16]. IaaS provides users with utilization services for all the computing infrastructure, including CPU, memory, storage, network, and other basic computing resources, where users can deploy and run any software. PaaS provides services for user development languages and tools (such as Java, Python, and .Net), and SaaS provides application services for user operators to publish applications that run on cloud computing infrastructure.

Intelligent cloud manufacturing has been extended and expanded on the basis of the above services. Based on that, this study constructs the intelligent cloud manufacturing resources integration and scheduling system for fully 
mechanized coal mining equipment, and the overall framework is presented in Fig. 2. The resource layer is used to collect, extract, and integrate all kinds of computing and manufacturing resources, and the virtual service layer is used to virtualize the resources and the virtual storage of data that can achieve remote extraction. The virtual layer also corresponds to the IaaS layer of cloud computing, and the global service layer includes all kinds of software frameworks, engines, data management and analysis, and middleware and cloud services that correspond to the PaaS layer of cloud computing. The application layer implements the relevant business applications of computing and manufacturing that correspond to the SaaS layer in cloud computing, and the user interface layer provides users with the necessary interface required to use the computing and manufacturing resources of each layer.

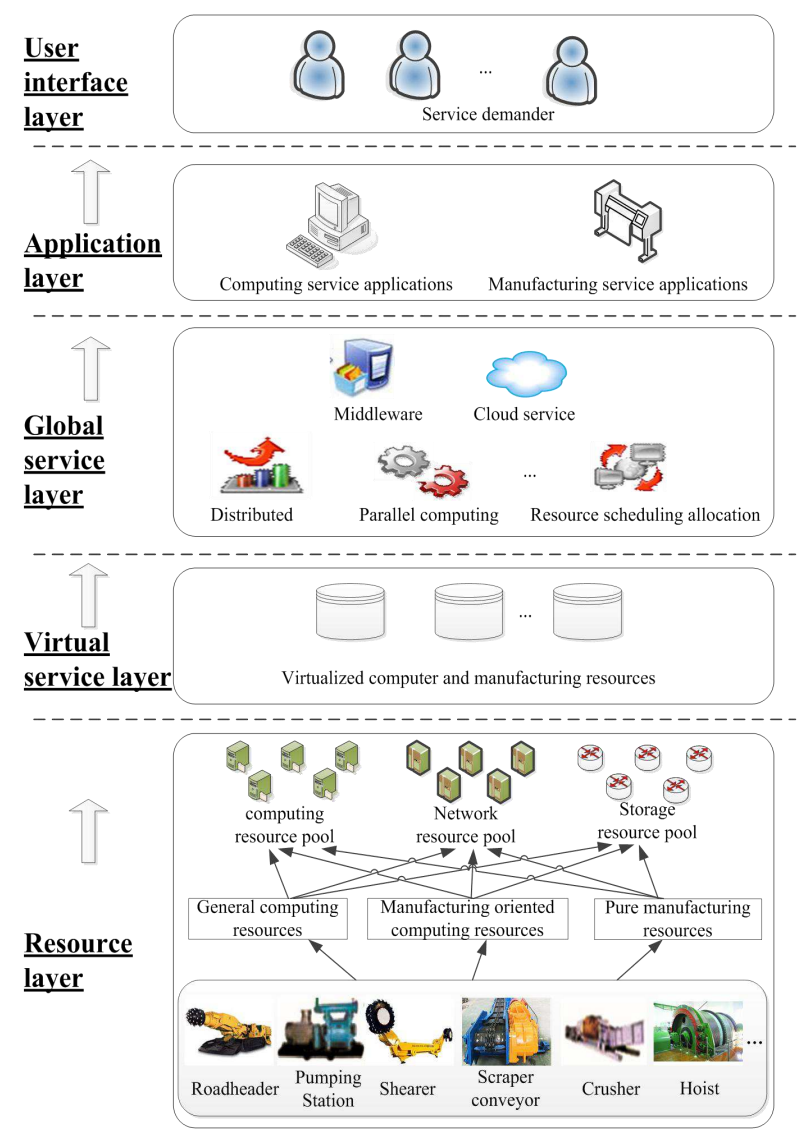

Fig.2 Overall framework of intelligent cloud manufacturing resources integration and scheduling system

\section{Cloud manufacturing resources integration system}

\subsection{System function and implementation}

In this study, based on the engineering background of large-scale mining and transportation equipment, such as shearers, scraper conveyors, pump stations, crushers, roadheaders, and mine hoists, the respective cloud manufacturing resources integration platforms were established to provide the corresponding sharing and service functions. Each system function includes a general technical service support system and a special technical service support system.

The general technical service support system includes the system introduction, design system, rules and standards, practical technology, related academic papers, technical training, and user assistance functions of all the equipment platforms for the fully mechanized mining equipment. On the other hand, the special technical service support functions include the model selection design, parametric modeling, virtual assembly and motion display, CAE analysis system, knowledge management system, key technologies and fault records, and general support system. The specific function structure is presented in Fig.3.

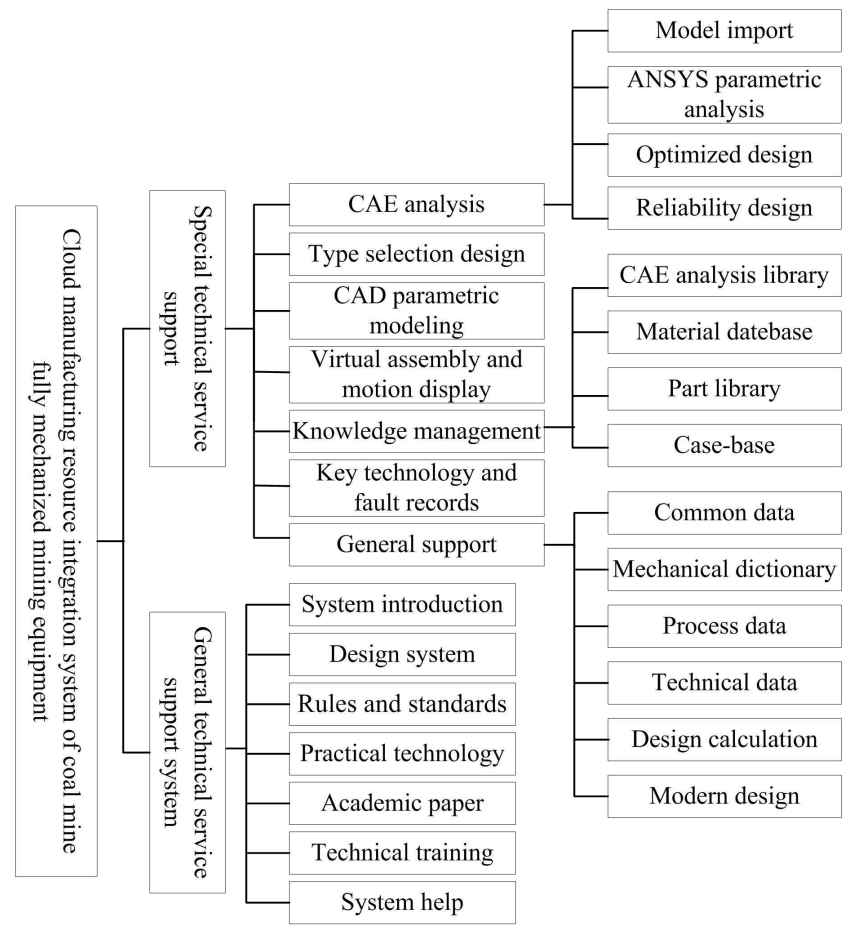

Fig.3 Function of resources integration system

The system integrates the key parts of shearer, scraper conveyor, roadheader, mine hoist and the digital design, manufacture and test resources of the whole machine.It can shorten the design cycle, reduce the R \& D cost, improve the product quality, optimize the equipment structure, improve the structure, stability and system dynamics performance of the whole machine and parts of fully mechanized coal mining equipment, improve the reliability of the equipment, and realize the digital collaborative design of fully mechanized coal mining equipment in the industrial Internet environment. 


\subsection{Function test}

Taking the scraper conveyor as an example, this study introduces the basic functions of a scraper conveyor intelligent cloud manufacturing resources integration system. It can be divided into the scraper conveyor type selection design, parametric modeling, virtual assembly and motion display, CAE analysis, knowledge management, key technology and fault record, general support system, and other relative functions. The type selection design is mainly based on the parameters related to the design productivity input by the user (coal seam thickness, shearer cutting depth, solid density of coal), working face length, shearer traction speed, inclination, scraper type (bendable, non-bendable), transportation direction (up, down), etc. Then, the system automatically outputs the scraper conveyor model matching parameters and relevant parameters in addition to the corresponding selection report. Parametric modeling is mainly based on CAD technology and the secondary development of the UG model. First, the key dimension parameters of the components need to be determined, the system develops the COM components of the parametric model, compiles them into a dynamic-link library, and then uses the model display page to realize the call of the dynamic-link library so as to complete the modeling and model display process. The virtual assembly and motion display mainly use unity $3 \mathrm{D}$ to build a virtual model of the equipment, and the CAE analysis function completes the static analysis, the non-prestressed model analysis, and the transient analysis of the CAE component. The knowledge of the management system mainly completes the sorting, integration, query, update, and management of the scraper conveyor design resources, and the key technology and fault recording function completes the query of the fault history, including the fault phenomenon, fault reason, and fault handling methods. Furthermore, the general support system can realize the query and calculation of the general data. Fig.4 presents the page of the CAE static analysis for the dumbbell pin parts of the scraper conveyor.

First, the dumbbell pin size parameters and the part analysis parameters are input into the system, as presented in Fig.4(a). Then, the background will conduct the CAE static analysis according to the input parameters and then provide the results after the analysis, as presented in Fig.4(b).

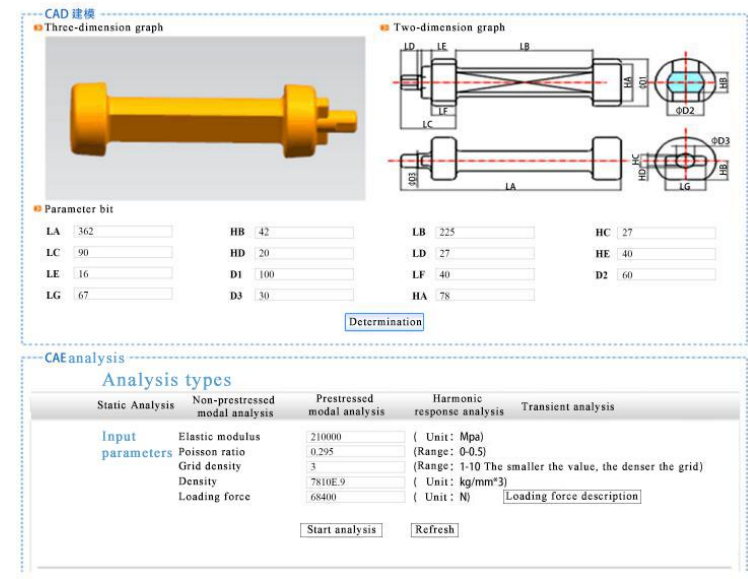

(a)Parameter input

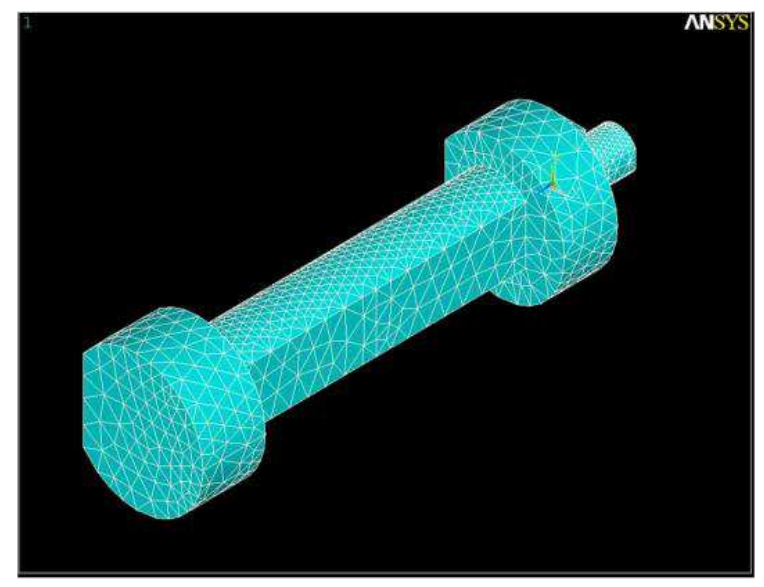

(b)Analysis results

Fig.4 Parametric CAE static analysis of dumbbell pin of scraper conveyor

4. Research on resources scheduling of intelligent cloud manufacturing for fully mechanized coal mining equipment

\subsection{Manufacturing resources scheduling scheme}

The cloud manufacturing resources of fully mechanized coal mining equipment are distributed in different geographical locations, with various types and specifications. The resources consumed by the design, simulation and manufacturing tasks of each coal machine are different. Therefore, the research of cloud manufacturing resource scheduling is particularly necessary [17]. In the process of manufacturing resources scheduling, firstly, through information technology, the available manufacturing resources are virtualized to form a set of rich and complete manufacturing services. When users put forward manufacturing tasks, they are divided into several sub tasks according to the product demand, manufacturing cost and time of the task, and manufacturing resources are integrated 
and scheduled in the cloud manufacturing resources integration and scheduling system source matching and scheduling, and finally determine the implementation plan. The manufacturing resources scheduling scheme is presented in Fig.5.

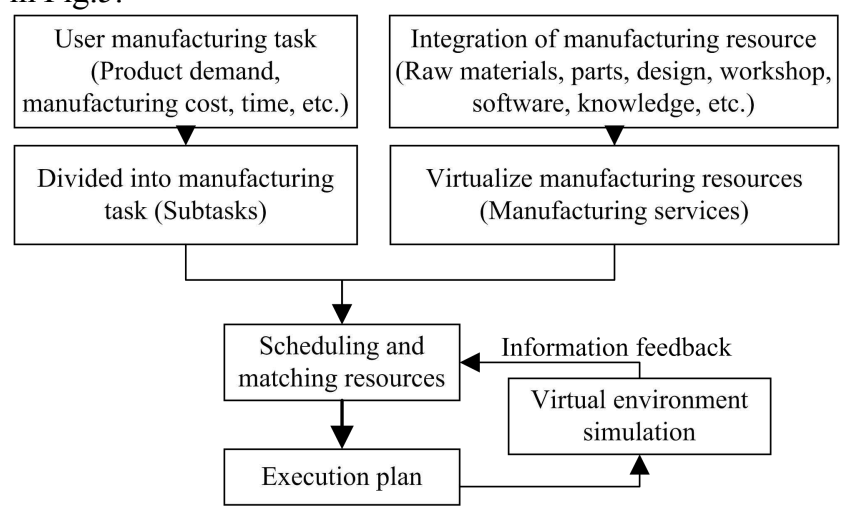

Fig.5 Manufacturing resources scheduling scheme

With the complexity of solving the resource scheduling problem, the scale of the combinatorial optimization problem will dramatically increase. Besides, using the traditional enumeration method to find the optimal solution will only make the solution time longer and decrease its accuracy. At present, the research on scheduling in a cloud manufacturing environment mainly focuses on the ant colony algorithm, genetic algorithm, particle swarm optimization algorithm, game algorithm, and other intelligent optimization algorithms [18-22]. Among them, the particle swarm optimization algorithm is suitable for solving real number problems, which are simple, easy to calculate, and fast to solve. However, it has some problems such as falling into a local optimum. The ant colony algorithm is suitable for solving the problem of path searching on a graph. However, due to the lack of pheromone in the initial stage, the time of accumulating pheromone in the initial stage of search is longer.The lack of a pheromone in the initial stage leads to the longtime of the accumulating pheromone in the initial stage of searching.

In comparison, the genetic algorithm has the advantage of not relying on gradient information or other auxiliary knowledge in the calculation process. Also, only the objective and fitness functions affect the search direction, which has strong robustness and is more suitable for the complex and diverse scheduling tasks in the cloud manufacturing platform. However, the genetic algorithm converges to the local optimal solution prematurely, that is, the problem of "prematurity" and the problem of low local searchability. In this study, a genetic algorithm with an adaptive operation is proposed to solve the scheduling problem of cloud manufacturing resources.

\subsection{A description of the manufacturing resources scheduling problem}

The scheduling method in the cloud manufacturing service system directly affects the final scheme of cloud manufacturing, which is an important part of the cloud manufacturing service system. Manufacturing resources scheduling is described as follows: a manufacturing task $F$ submitted by the user, which contains $l$ phase tasks $F_{1}, F_{2}, F_{3}, \ldots, F_{l}$, where $F_{k}(1 \leq k \leq l)$ denotes the $k$ phase task. Then, each phase task is divided into $n$ subtasks $F_{k 1}, F_{k 2}, F_{k 3}, \ldots, F_{k n}$, where $F_{k i}\left(F_{k i}(1 \leq i \leq n)\right)$ denotes the $i$ subtask in the $k$ phase task. The subtask $F_{k i}$ has $m$ optional services $V_{k i 1}, V_{k i 2}, V_{k i 3}, \ldots, V_{k i m}$ in the cloud manufacturing platform, where $V_{k i j}(1 \leq j \leq m)$ denotes the $j$ service of the subtask $i$ in phase $k$. Then, the corresponding relation between $F_{k}$ and $V$ can be expressed by the relation matrix $X$ :

$$
X_{k}=\left[\begin{array}{cccc}
x_{k 11} & x_{k 12} & \cdots & x_{k 1 n} \\
x_{k 21} & x_{k 22} & \cdots & x_{k 2 n} \\
\cdots & \cdots & \cdots & \cdots \\
x_{k m 1} & x_{k m 2} & \cdots & x_{k m n}
\end{array}\right] \text {. The decision-making }
$$

of each subtask is defined as $x_{k i}(1 \leq i \leq n, 1 \leq j \leq m 1 \leq k \leq 1), x_{k i j} \in\{(01\}$, where $x_{k i j}=1$ indicates that the subtask $i$ of the phase $k$ task selects the $j$ service. $x_{k i j}=0$ indicates that the subtask $i$ of the phase $k$ task does not select the $j$ service, and the expected time for the $j$ service completion of the subtask $i$ of the phase $k$ task is defined as $t_{k i j}$. The manufacturing cost is defined as $e_{k i j}$, and the satisfaction is positioned as $a_{k i j}$. In this manufacturing task, the time of a subtask is $T_{k i}=\sum_{j=1}^{m}\left(t_{k i j} \times x_{k i j}\right) \quad$, the manufacturing cost is $E_{k i}=\sum_{j=1}^{m}\left(e_{k i j} \times x_{k i j}\right) \quad, \quad$ and the satisfaction is $A_{k i}=\sum_{j=1}^{m}\left(a_{k i j} \times x_{k i j}\right)$.

In summary, the total duration of the manufacturing task is

$$
\begin{array}{r}
T=\sum_{k=1}^{l}\left(\max \left\{\sum_{j=1}^{m}\left(t_{k i j} \times x_{k i j}\right)\right\}\right) \text {, the total cost is } \\
E=\sum_{k=1}^{l} \sum_{i=1}^{n} \sum_{j=1}^{m}\left(e_{k i j} \times x_{k i j}\right) \text {, and the final satisfaction } \\
\text { is } A=\sum_{k=1}^{l} \sum_{i=1}^{n} \sum_{j=1}^{m}\left(a_{k i j} \times x_{k i j}\right) .
\end{array}
$$




\subsection{Multi-objective resources scheduling based on the adaptive genetic algorithm}

The genetic algorithm is a computational model that simulates the natural evolution and biological mechanism of Darwin's biological evolution theory, and it is a method for searching for the optimal solution by simulating the natural evolution process. The general process of the genetic algorithm is presented in Fig.6.

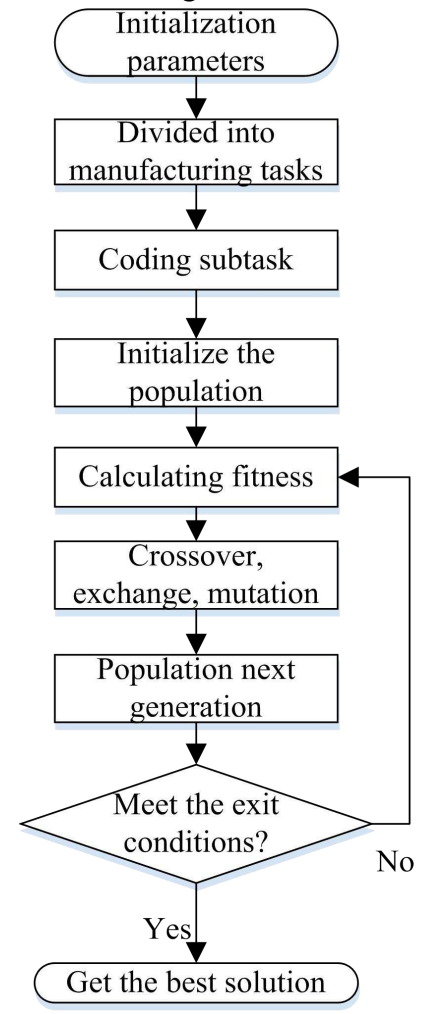

Fig.6 Manufacturing resources scheduling scheme

\section{(1) Coding}

According to the characteristics of the scheduling model, a binary coding method based on phase tasks and subtasks is selected, and the candidate services are randomly selected according to the sequence of the subtasks for coding. The coding length is determined by the number of phase tasks, the number of subtasks in each phase, and the number of optional services in the subtasks.

(2) Calculate fitness function

Taking the manufacturing time, manufacturing cost, and final satisfaction as objective functions, the fitness function of the task is defined as:

$$
\begin{aligned}
F & =a T_{0}+b E_{0}+c A_{0} \\
T_{0} & =\sum_{k=1}^{l} \sum_{i=1}^{n} \frac{T_{\max }-T_{k i}}{T_{\max }-T_{\min }} \\
E_{0} & =\sum_{k=1}^{l} \sum_{i=1}^{n} \frac{E_{\max }-E_{k i}}{E_{\max }-E_{\min }} \\
A_{0} & =\sum_{k=1}^{l} \sum_{i=1}^{n} \frac{A_{k i}-A_{\min }}{A_{\max }-A_{\min }}
\end{aligned}
$$

where $\mathrm{a}, \mathrm{b}$, and $\mathrm{c}$ denote the weight of time, cost, and satisfaction, respectively, meeting the requirements of $\mathrm{a}+\mathrm{b}$ $+\mathrm{c}=1 . \mathrm{T}_{0}, \mathrm{E}_{0}$, and $\mathrm{A}_{0}$ denote the total length of the manufacturing service, the total manufacturing cost, and the final manufacturing satisfaction after normalization, respectively. $T_{\max }=\max \left\{T_{k i}\right\}, T_{\min }=\min \left\{T_{k i}\right\}$, and so on.

In summary, the goal of scheduling an algorithm is to find an optimal relation matrix $X_{k}$ in each stage task so that the fitness function $F$ can get the maximum value.

(3)Selection operation

The probability of the individual $i$ in entering the next generation is directly related to its fitness function value and the selection probability

$$
P_{\mathrm{s}}=1-F_{i} / \sum_{i=1}^{k} F_{i}
$$

, where $k$ is the number of individuals in the population, and $F_{i}$ is the fitness value of the $i$ th subtask.

(4)Crossover and mutation operation

The crossover and mutation operations are based on the services selected by the subtasks. One or more subtasks that need to be crossed and mutated are randomly selected for the crossover and mutation operations of the service selection. In the early stage of the algorithm iteration, due to the randomness of its generation, there are great differences among the individuals, and increasing the probability of mutation and crossover can make it converge quickly. In the later stage of the algorithm iteration, the difference among the individuals in the population is small, and reducing the probability of mutation and crossover can retain the excellent gene structure generated by the iteration and make the algorithm converge quickly. The generation $g$ crossover probability is represented by

$$
\begin{aligned}
& P_{c(g)}=\left(F_{e}^{2}+F_{c}^{2}\right)^{\frac{1}{2}} \times\left(1-\frac{g}{G}\right) \\
& F_{e}=\left(F_{\text {max }}-F_{a v g}\right) /\left(F_{\text {max }}-F_{\text {min }}\right) \\
& F_{c}=\left(F_{\text {max }}-F_{f}\right) /\left(F_{\text {max }}-F_{\text {min }}\right)
\end{aligned}
$$


where $P_{c(g)}$ denotes the crossover probability of the $g$ th generation, and $G$ denotes the total number of iterations. $F_{\max }$ and $F_{\text {max }}$ denote the maximum and minimum fitness values, respectively, and $F_{\text {avg }}$ and $F_{f}$ denote the average fitness values and the fitness values of the larger individuals among the two crossover parents, respectively.

The mutation probability of an individual in the generation $g$ th is represented by

$$
P_{m(t)}=\frac{F_{m}}{1+F_{e}} \times \frac{\arctan \left(g^{\frac{1}{2}}\right)}{\pi}
$$

$$
F_{m}=\left(F_{\max }-F_{f}\right) /\left(F_{\max }-F_{\min }\right)
$$

\subsection{Experimental verification}

Taking the roadheader as an example, the resource scheduling problem in its cloud manufacturing process verifies the applicability of this algorithm model. The manufacturing project of the roadheader includes the design, manufacturing, assembly, and other production stages. Each stage task contains several subtasks, and each subtask has several optional services. Some service resources matched in the cloud manufacturing service system are presented in Table 1 .

\begin{tabular}{|c|c|c|c|c|c|c|c|c|c|c|c|c|c|c|c|c|c|c|c|c|c|c|c|c|c|c|c|}
\hline \multirow{3}{*}{$\begin{array}{c}\text { Phased mission } \\
\text { Subtask } \\
\text { Additional } \\
\text { service }\end{array}$} & \multicolumn{6}{|c|}{1} & \multicolumn{9}{|c|}{2} & \multicolumn{6}{|c|}{3} & \multicolumn{6}{|c|}{4} \\
\hline & \multicolumn{2}{|c|}{1} & \multicolumn{4}{|c|}{2} & \multicolumn{3}{|c|}{1} & \multicolumn{4}{|c|}{2} & \multicolumn{2}{|c|}{3} & \multicolumn{2}{|c|}{1} & \multicolumn{2}{|c|}{2} & \multicolumn{2}{|c|}{3} & \multicolumn{5}{|c|}{1} & \multirow{2}{*}{$\begin{array}{l}\ldots \\
\ldots\end{array}$} \\
\hline & 1 & 2 & 1 & 2 & 3 & 4 & 1 & 2 & 3 & 1 & 2 & 3 & 4 & 1 & 2 & 1 & 2 & 1 & 2 & 1 & 2 & 3 & 1 & 2 & 3 & 4 & \\
\hline $\begin{array}{c}\text { Required } \\
\text { time(hours) }\end{array}$ & 40 & 28 & 22 & 26 & 42 & 37 & 25 & 30 & 22 & 60 & 48 & 72 & 43 & 35 & 21 & 24 & 27 & 18 & 12 & 42 & 28 & 30 & 28 & 38 & 50 & 70 & $\cdots$ \\
\hline $\begin{array}{c}\text { Required } \\
\text { cost(thousands) }\end{array}$ & 47 & 20 & 35 & 35 & 60 & 50 & 70 & 88 & 73 & 81 & 90 & 75 & 90 & 77 & 90 & 33 & 25 & 19 & 22 & 60 & 73 & 65 & 60 & 46 & 45 & 39 & $\cdots$ \\
\hline $\begin{array}{l}\text { Satisfaction } \\
\text { (quality etc.) }\end{array}$ & 76 & 49 & 67 & 67 & 80 & 78 & 71 & 65 & 78 & 65 & 79 & 59 & 83 & 65 & 91 & 75 & 62 & 88 & 65 & 77 & 83 & 80 & 92 & 74 & 79 & 88 & $\cdots$ \\
\hline
\end{tabular}

Table 1 Some resources in the Cloud Manufacturing platform

The algorithm is implemented as follows:

(1) Initialization parameters

Taking the population number 10 as an example to illustrate the implementation process of the algorithm, the maximum genetic algebra is set to 100 , and the required time, required cost, and final satisfaction weight are $0.4,0.4$, and 0.2 , respectively.

\section{(2) Coding}

Using a binary encoding method based on the phase task and subtask, this task has 4 phase tasks, 9 subtasks, and 23 optional services. The coding diagram is presented in Fig.7.

$$
\begin{array}{l:l|l:l:l|l:l:l|l}
0 & 11 & 01 & 0 & 1 & 0 & 0 & 10 & 10 \\
\text { Phase 1 } & \text { Phase2 } & & \text { Phase 3 Phase 4 }
\end{array}
$$

Fig.7 Coding diagram

(3) Selection operation

Randomly generating the initial population, calculating the fitness value of each individual, and making a generation selection. The selection operation is presented in Table 2.
Table 2 Selection operation

\begin{tabular}{rrrrrrr}
\hline $\begin{array}{c}\text { Indivi } \\
\text {-dual }\end{array}$ & $\begin{array}{c}\text { Chromo } \\
\text {-some }\end{array}$ & $\begin{array}{c}\text { Fit } \\
\text {-nes }\end{array}$ & $\begin{array}{c}\text { Selection } \\
\text { probability }\end{array}$ & $\begin{array}{c}\text { Number of } \\
\text { selection }\end{array}$ & $\begin{array}{c}\text { Selection } \\
\text { result }\end{array}$ \\
\hline 1 & 01101011001010 & 2.306 & 0.123 & 3 & 1101011001010 \\
2 & 00110010110101 & 1.174 & 0.063 & 0 & 1101011001010 \\
3 & 00001111100110 & 2.145 & 0.115 & 1 & 1101011001010 \\
4 & 11010011100100 & 1.725 & 0.092 & 0 & 0001111100110 \\
5 & 10001010011010 & 1.281 & 0.069 & 1 & 0001010011010 \\
6 & 00100001100010 & 1.863 & 0.010 & 0 & 0001110111011 \\
7 & 00001110111011 & 2.889 & 0.155 & 2 & 0001110111011 \\
8 & 11001101000010 & 1.377 & 0.074 & 0 & 0101100110100 \\
9 & 00101100110100 & 1.785 & 0.096 & 2 & 0101100110100 \\
10 & 11010100110011 & 2.132 & 0.114 & 1 & 1010100110011 \\
\hline
\end{tabular}

(4) Crossover operation

First, the population was randomly paired. Then, the intersection location was set up with phase tasks and random blocks, and finally, the exchange was carried out according to the crossing probability $P_{\mathrm{c}}$. The cross operation is presented in Table 3. 
Table 3 Crossover operation

\begin{tabular}{|c|c|c|c|c|}
\hline & Chromosome & Match result & $\begin{array}{l}\text { Crossover } \\
\text { probability }\end{array}$ & Cros \\
\hline 1 & 011010110 & 01101 & & 011 \\
\hline 2 & 01101011001010 & $00001 \quad 111100110$ & & 00001 \\
\hline 3 & 01101011001010 & $0110101100 \quad 1010$ & \multirow[b]{2}{*}{0.589} & 011010 \\
\hline 4 & 00001111100110 & $0000111011 \quad 1011$ & & 000 \\
\hline 5 & 1000 & 01101011001010 & \multirow{2}{*}{0.732} & 011 \\
\hline 6 & 0000 & $001 \quad 01100110$ & & 00 \\
\hline 7 & 0000 & 100010100 & & 0000 \\
\hline 8 & 00101 & 110101001 & & 110 \\
\hline 9 & 0010 & $00001110 \quad 111011$ & \multirow{2}{*}{0.839} & 0000 \\
\hline 10 & 11010100110011 & 00101100 & & 00101100111011 \\
\hline
\end{tabular}

(5) Mutation operation

First, the positions of the mutation points of each individual were randomly generated, where the number of the mutation points indicates the sequence of the subtasks on the chromosome. Then, the genes were randomly mutated according to the mutation probability $p_{m}$. The mutation operation is presented in Table 4.

Table 4 Mutation operation

\begin{tabular}{|c|c|c|c|c|}
\hline \multicolumn{2}{|c|}{$\begin{array}{l}\text { Indivi Chromosome } \\
\text {-dual }\end{array}$} & Mutation point & $\begin{array}{l}\text { Mutation } \\
\text { probability }\end{array}$ & \multirow{3}{*}{$\begin{array}{c}\begin{array}{c}\text { Mutation } \\
\text { results }\end{array} \\
01101011001010\end{array}$} \\
\hline$\overline{1}$ & 01101011001010 & 4 & 0.286 & \\
\hline \multirow[b]{2}{*}{2} & & $\begin{array}{lll}01101 & 01 & 1001010\end{array}$ & \multirow[b]{2}{*}{0.843} & \\
\hline & 01101011001011 & 5 & & 01101010001011 \\
\hline \multirow[t]{2}{*}{3} & 01101011001011 & 2 & \multirow{2}{*}{$1^{0.365}$} & \multirow[t]{2}{*}{01101011001011} \\
\hline & & $\begin{array}{lll}0 & 11 & 01011001011\end{array}$ & & \\
\hline 4 & 00001110111010 & $00001110 \quad 1 \quad 11010$ & $0^{0.572}$ & 00001110111010 \\
\hline \multirow[t]{2}{*}{5} & \multirow[t]{2}{*}{01101100110100} & 2 & \multirow{2}{*}{$0^{0.821}$} & \multirow[t]{2}{*}{01001100110100} \\
\hline & & $\begin{array}{lll}0 & 11 & 01100110100\end{array}$ & & \\
\hline 6 & 00101011001010 & 7 & 0.504 & 00101011001010 \\
\hline 7 & 10001010010011 & $\begin{array}{cc}1 & 1 \\
1 & 0001010010011\end{array}$ & $1^{0}$ & 10001010010011 \\
\hline \multirow[t]{2}{*}{8} & \multirow[t]{2}{*}{11010100111010} & 3 & \multirow{2}{*}{$0^{0.743}$} & \multirow[t]{2}{*}{11001100111010} \\
\hline & & $\begin{array}{lll}110 & 10 & 100111010\end{array}$ & & \\
\hline 9 & 00001110110100 & $\begin{array}{ccc}{ }^{7} & \\
000011101 & 1 & 0100\end{array}$ & 0.543 & 00001110100100 \\
\hline 10 & 00101100111011 & $\begin{array}{c}9 \\
001011001110\end{array}$ & 0.372 & 00101100111011 \\
\hline
\end{tabular}

(6) Recycling operation

Repeat the above steps 3, 4, and 5 and select the optimal individual according to the order of the fitness value. When the convergence condition is met or the maximum number of iterations is reached, the optimal individual is decoded, and the scheduling result is output.

By programming in MATLAB, after setting the initial parameters, the obtained curve of the number of iterations and the fitness value is presented in Fig.8. It can be seen from the figure that the maximum fitness value appears when iterating 32 times and when the corresponding code of the best service scheme is 10010111010110 . The output scheduling scheme after transcoding is as follows: the selected service number of two subtasks in phase I is 2,1 ; the selected service number of three subtasks in phase II is 3, 4, 2 ; the selected service number of three subtasks in phase III is $1,2,2$; and the selected service number of one subtask in phase IV is 3 . Under the condition that the subtasks of each phase can be carried out at the same time, the manufacturing task plan needs $149 \mathrm{~h}$ (the total cumulative time of each subtask is $250 \mathrm{~h}$ ), the cost is 481 thousand RMB, and the expected final satisfaction is 670 .

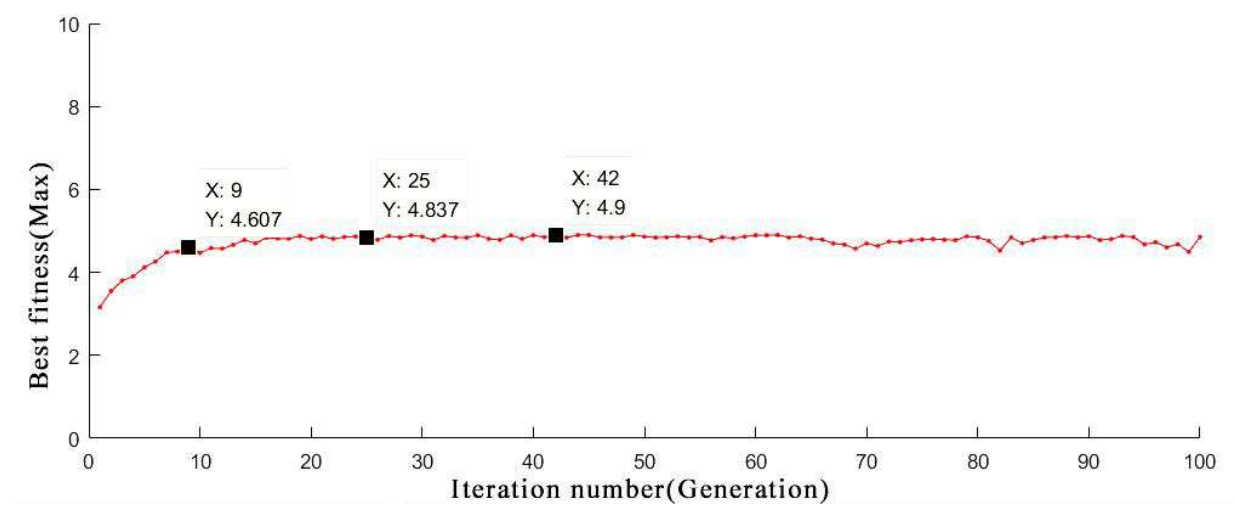

Fig.8 The curve of iteration degree and fitness value 
The results reveal that the algorithm model has the potential to be used for global search and that the result is more accurate and has a fast convergence speed, which is ideal for manufacturing resources scheduling.

At present, the "Intelligent cloud manufacturing resources integration and scheduling system for coal mining equipment" has been successfully launched, and it is welcomed by many coal machinery equipment manufacturing enterprises and coal mine design institutes in Shanxi province and China, especially the functions of type selection design and CAE analysis of coal mine machinery and equipment, which makes more than 10 application enterprises.It improves the technological innovation ability and the reuse ability of knowledge assets of application enterprises, drives a batch of application and technology research and system development, and brings considerable economic benefits to the above application units.

\section{Conclusions}

(1)Nowadays, there is a strong demand for intelligent cloud manufacturing resources and services in the field of fully mechanized coal mining equipment. The intelligent cloud manufacturing service system for fully mechanized coal mining equipment can realize the integration and sharing of resources, such as the design, calculation, data, simulation, and services of coal mining and transportation equipment in the cloud manufacturing environment, and it has a broad development space.

(2)The resources integration system has realized the digital designs, manufacturing, and testing of the key parts and complete machines of fully mechanized coal mining equipment. The system can improve the structure, stability, and system dynamic performance of the whole machine and parts of the fully mechanized mining equipment, shorten the design cycle, reduce the $R \& D$ cost, improve the reliability of the equipment, and realize the digital collaborative design and manufacturing of the fully mechanized coal mining equipment in the industrial Internet environment.

(3)The cloud manufacturing resources scheduling method that is based on the adaptive genetic algorithm can obtain more accurate scheduling results with the potential to be used for global search. Moreover, it has a fast convergence speed and is an ideal method for solving manufacturing resources scheduling.

\section{References}

1. M. G. Mehrabi, A. G. Ulsoy, Y. Koren. (2000)Reconfigurable manufacturing systems: Key to future manufacturing. Journal of Intelligent Manufacturing. 11(4):403-419.

2. L. Nolting, J. Priesmann, C.Kockel, et al.(2019) Generating transparency in the worldwide use of the terminology industry 4.0, Applied Sciences. 9(21):4659 .
3. J. Zhou(2015)Intelligent manufacturing —-main direction of "made in China 2025". China Mechanical Engineering, 26(17):2273-2284.

4. B. Li , L. Zhang, S. Wang, et al.(2010)Cloud manufacturing---a new service-oriented networked manufacturing model. Computer Integrated Manufacturing Systems.16(1):1-7 .

5. B. Li, L. Zhang, L. Ren, et al.(2012)Typical characteristics, technologies and applications of cloud manufacturing. Computer Integrated Manufacturing Systems. 18(7):1345-1356.

6. B. Li, X. Chai, L. Zhang.(2016)Smart cloud manufacturing: a new kind of manufacturing paradigm, approach and ecosystem of deep integration of the internet and the manufacturing industry. ZTE Technology Journal.22(5):2-6 .

7. Y. Liu, L. Wang.(2018)Cloud manufacturing: latest advancements and future trends. Procedia Manufacturing. 25:62-73.

8. G. Adamson, L. Wang, M. Holm.(2017)Cloud manufacturing: a critical review of recent development and future trends. International Journal of Computer Integrated Manufacturing.30(4/5):347-380.

9. X. Wang, Z. Yang, H. Ding, et al.(2018)Research and application on coal mine machinery equipment cloud manufacturing resource service platform. Journal of China Coal Society.38(10): 1888-1893.

10. A. Cai, Z. Guo, S. Guo, et al. (2019)Optimization strategy of knowledge service composition in cloud manufacturing environment.Computer Integrated Manufacturing Systems. 25(2):421-430.

11. S. Huang, B. Huang. (2018)Security architecture for cloud manufacturing platform. Computer Integrated Manufacturing Systems.24(4):851-861.

12. L. Zhou, L. Zhan, Y. Liu.(2017)Survey on scheduling problem in cloud manufacturing.Computer Integrated Manufacturing Systems.23(6):1147-1166.

13. Y. Liu, L. Wang, X. Wang, et al.(2018)A Revisit to cloud manufacturing. China Mechanical Engineering,29(18):2226-2237.

14. X. Xu.(2012)From Cloud Computing to cloud manufacturing. Robotics and Computer Integrated Manufacturing. 28(1):75-86.

15. X. Lu, S. Kan.(2019)Geological guarantee and transparent geological cloud computing technology of precision coal mining. Journal of China Coal Society., 44(8):2296-2305.

16. V. Sharma, D. N. Jayakody, M. Qaraqe.(2020) Osmotic computing-based service migration and resource scheduling in Mobile Augmented Reality Networks (MARN). Future Generation Computer Systems-the International Journal of Escience, 102(1): 723-737. 
17. G. Jiang, M. Fan , L. Li. (2016)A cloud platform for remote diagnosis of breast cancer in mammography by fusion of machine and human intelligence. Conference on Medical Imaging - PACS and Imaging Informatics Next Generation and Innovations, San Diego, Feb 28-29.

18. W. Zheng, S. Wang, L. Kang, et al. (2017)Service composition based on double-layer ant colony algorithm in cloud manufacturing. Computer Integrated Manufacturing Systems.23(10):2269-2278 .

19. T. Gao , H. Yu, G. Fan. (2019)Simulated annealing genetic algorithm based approach to cloud resource scheduling. Journal of East China University of Science and Technology. 45(3):471-477.

20. X. Wang, X. Liu.(2018)Clouding computing resource scheduling based on double fitness dynamic genetic algorithm. Computer Engineering and Design, 39(5):1372-1376.

21. R. Sa.(2017)Cloud Computing Resource Scheduling Scheme Based on Ant Colony Particle Swarm Optimization Algorithm. Journal of Jilin University(Science Edition).55(6):1518-1522 .

22. J. Zhang, W. Xia, B. Huang, et al.(2018)Joint resource allocation scheme based on evolutionary game for mobile edge computing. Journal of Southeast University(English Edition).34(4):415-422. 


\section{Authors:}

Juanli $\mathrm{Li}$ is an associate professor of Mechanical and Vehicle Engineering in Taiyuan University of Technology, Taiyuan, China. She conducted and participated in several national and provincial research projects. She supervised several masters students. Her research interests include modern mechanical design theory and method, virtual reality design of mechanical product, and mechanical equipment status monitor and fault diagnosis.

Mengzhen Sun is a graduate student at Taiyuan University of Technology, majoring in Industrial Design Engineering. She is expected to receive a master's degree in engineering in two years. She mainly participated in the project of monitoring interface design and virtual reality technology development of fully mechanized mining equipment.

Jiacheng Xie received the B.Eng., M.Eng., and Ph.D. degrees from the Taiyuan University of Technology,
Taiyuan, China, in 2012, 2015, and 2018, respectively, all in Mechanical Engineering, where he is currently a Lecturer. He has performed many works mainly associated with virtual reality and modern design in coal mine equipment, such as virtual assembly and simulation system of mining, driving, and transporting equipment.

Shuo Jiang received his B.Eng. Degree in Mechanical Engineering in 2018 and is currently a master student at Taiyuan University of Technology. His main research direction is modern mechanical design theory and method. 
Figures

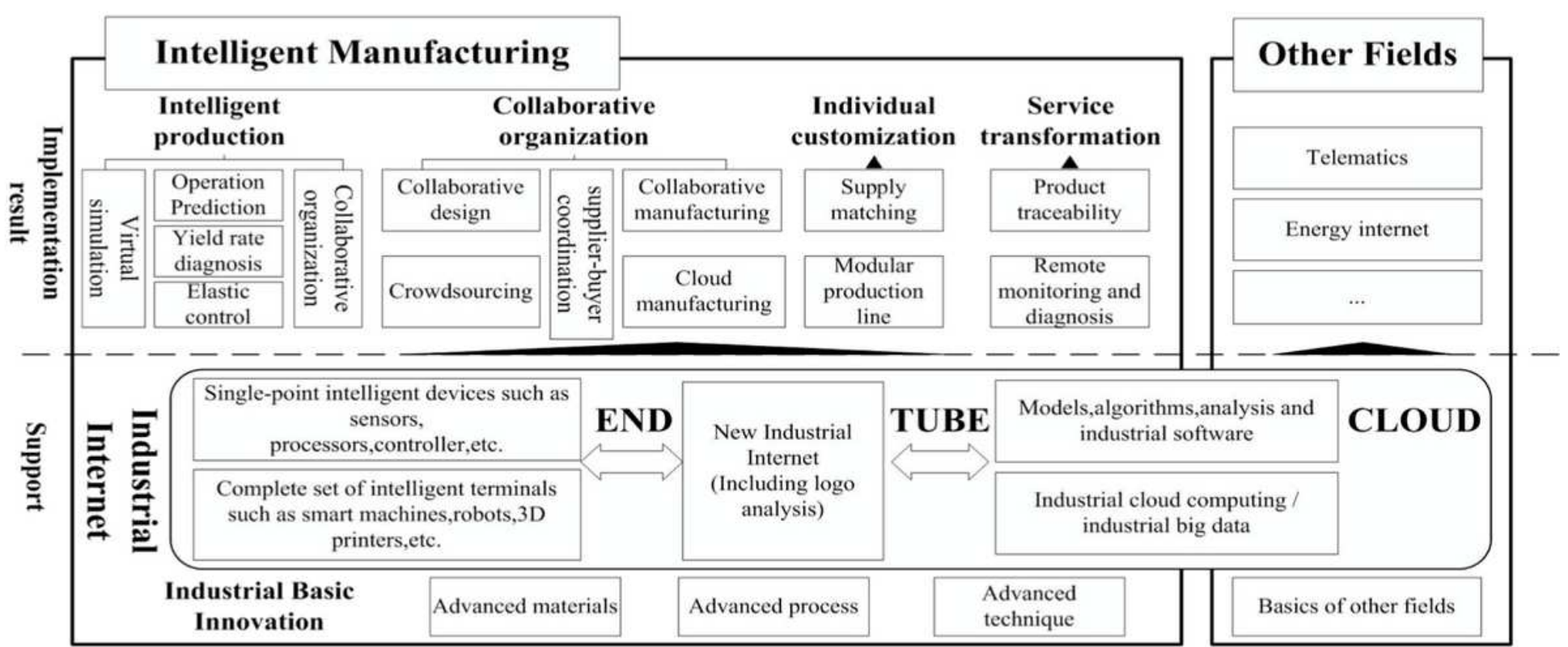

\section{Figure 1}

The supporting frame of industrial internet 

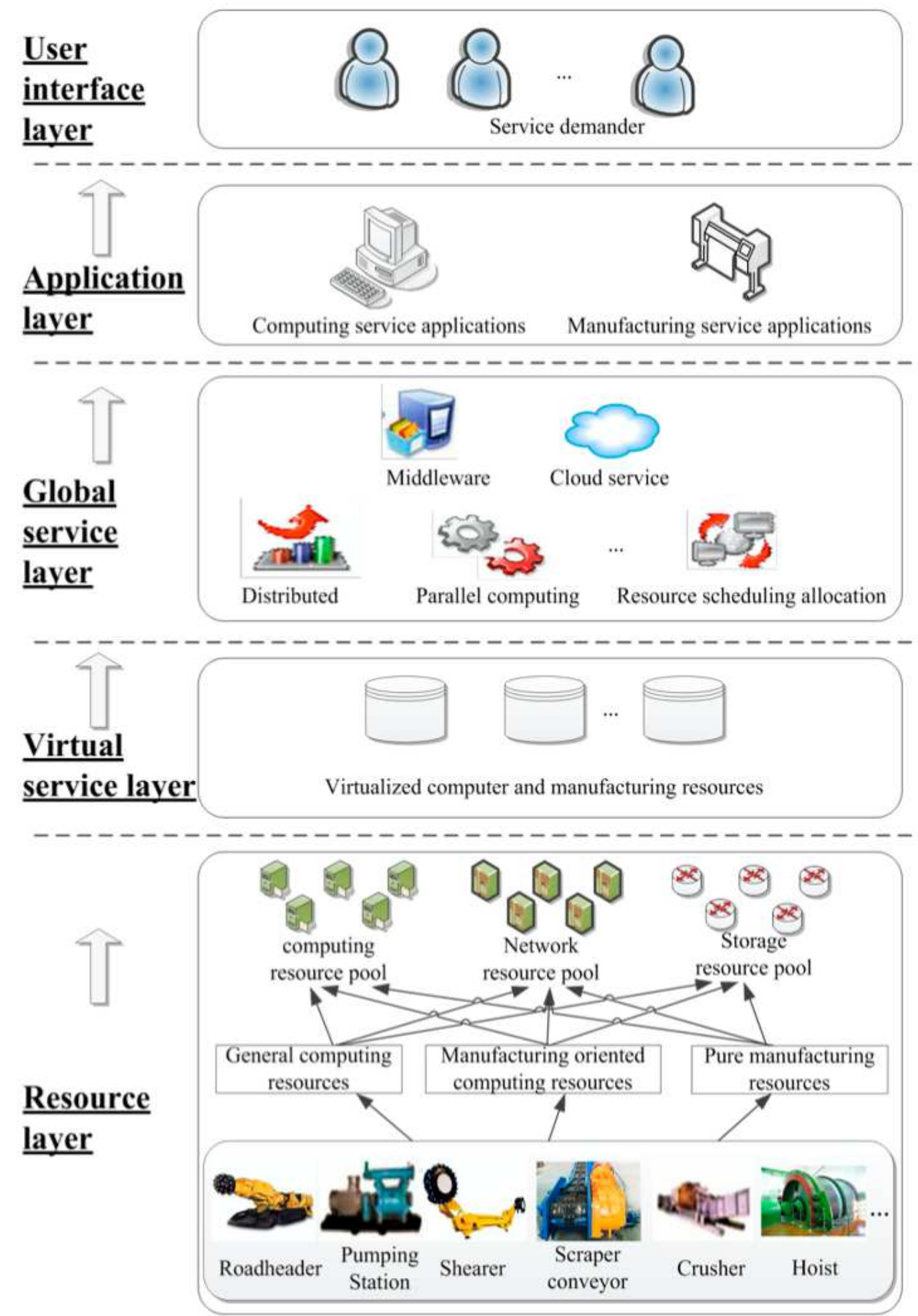

\section{Figure 2}

Overall framework of intelligent cloud manufacturing resources integration and scheduling system 


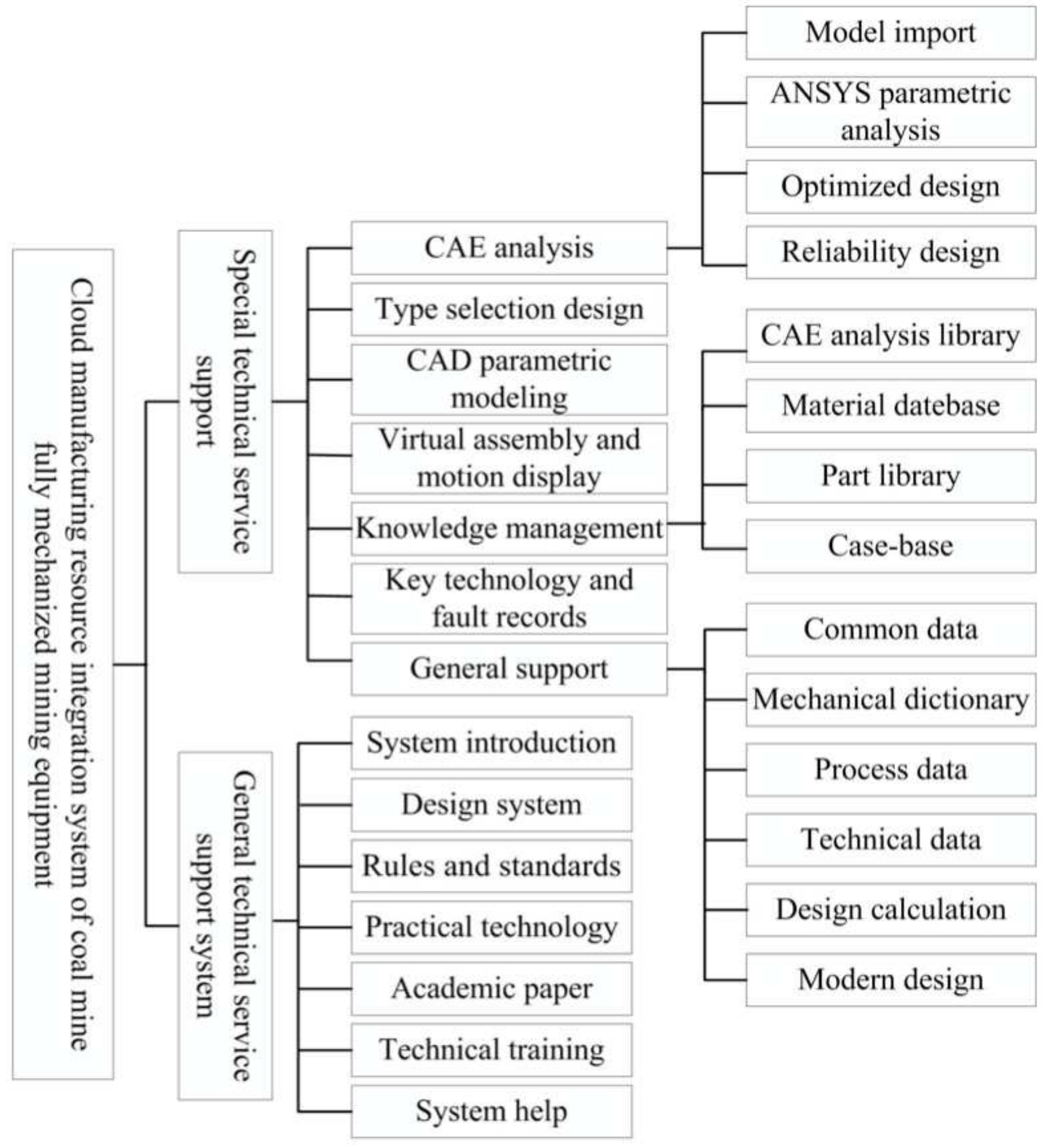

Figure 3

Function of resources integration system 


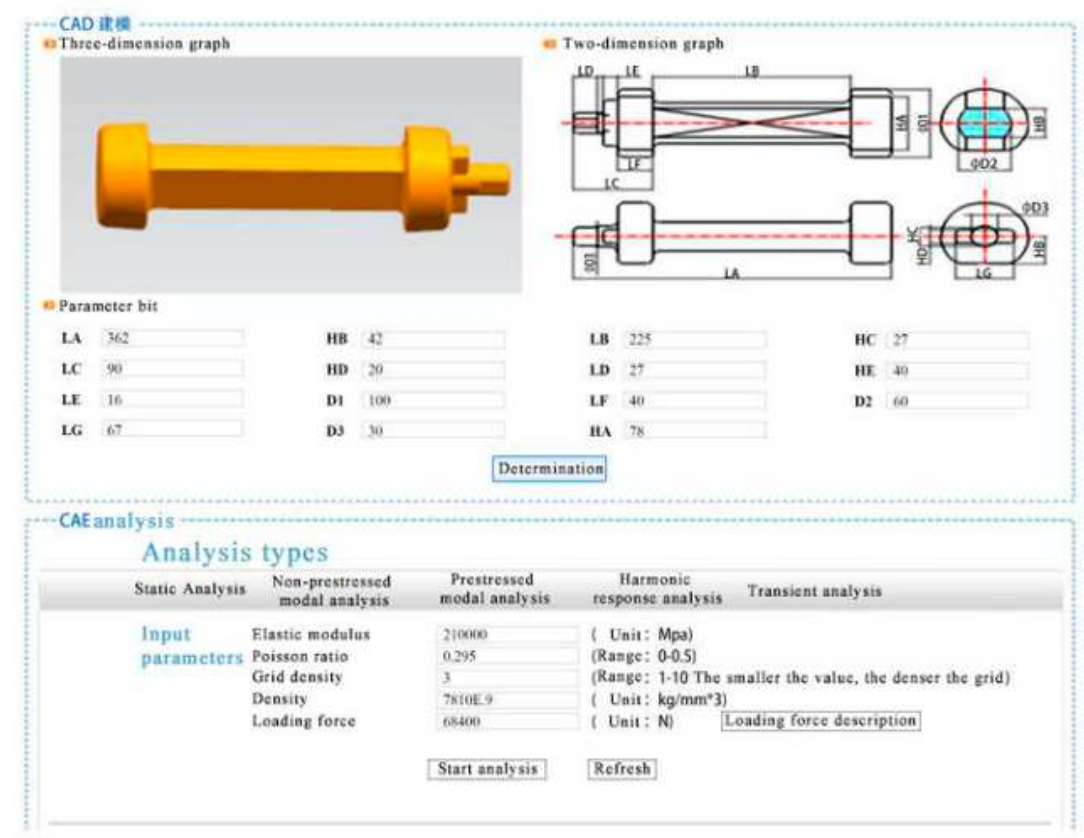

\section{(a)Parameter input}

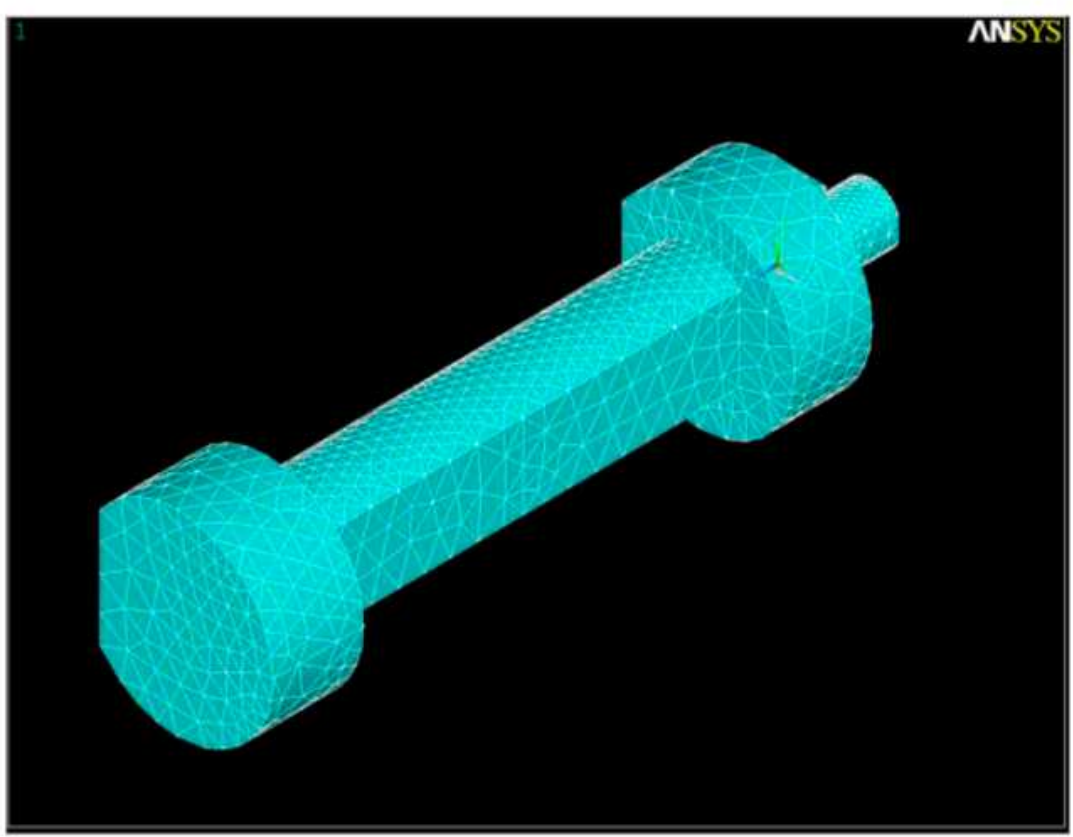

(b)Analysis results

Figure 4

Parametric CAE static analysis of dumbbell pin of scraper conveyor 